\title{
NUMERICAL SIMULATION OF THE TREATMENT OF SOIL SWELLING USING GRID GEOCELL COLUMNS
}

\author{
Mohammed Y. FATTAH ${ }^{1 *}$, Raid R. AL-OMARI ${ }^{2}$, Haifaa A. ALI ${ }^{3}$
}

\begin{abstract}
In this paper, a method for the treatment of the swelling of expansive soil is numerically simulated. The method is simply based on the embedment of a geogrid (or a geomesh) in the soil. The geogrid is extended continuously inside the volume of the soil where the swell is needed to be controlled and orientated towards the direction of the swell. Soils with different swelling potentials are employed: bentonite base-Na and bentonite base-Ca samples in addition to kaolinite mixed with bentonite. A numerical analysis was carried out by the finite element method to study the swelling soil's behavior and investigate the distribution of the stresses and pore water pressures around the geocells beneath the shallow footings. The ABAQUS computer program was used as a finite element tool, and the soil is represented by the modified Drucker-Prager/ cap model. The geogrid surrounding the geocell is assumed to be a linear elastic material throughout the analysis. The soil properties used in the modeling were experimentally obtained. It is concluded that the degree of saturation and the matric suction (the negative pore water pressure) decrease as the angle of friction of the geocell column material increases due to the activity of the sand fill in the dissipation of the pore water pressure and the acceleration of the drainage through its function as a drain. When the plasticity index and the active depth (the active zone is considered to be equal to the overall depth of the clay model) increase, the axial movement (swelling movement) and matric suction, as a result of the increase in the axial forces, vary between this maximum value at the top of the layer and the minimum value in the last third of the active depth and then return to a consolidation at the end of the depth layer.
\end{abstract}

\section{Address}

1 Building and Construction Engineering Department, University of Technology, Baghdad, Iraq

2 Civil Engineering Department, College of Engineering, AlNahrain University, Baghdad, Iraq

3 Department of Civil Engineering, College of Engineering, University of Baghdad, Baghdad, Iraq

* Corresponding author: myf_1968@yahoo.com

\section{Key words}

- Finite elements,

- simulation,

- swelling,

- geocell columns,

- saturation.

\section{INTRODUCTION}

Expansive soils are characterized as problematic as they exhibit swelling with the absorption of water and shrinking with its adsorption. Such changes in volume caused by swelling and shrinkage movements often distress an infrastructure that is not designed to withstand those movements. In addition to swelling, shrinkage-related changes in volume are critical in influencing the overall changes in the volume properties of the soil. Field conditions that promote shrinkage or shrinkage-induced crack formation include 
environmental changes, the construction process, and surcharge loading. Environmental changes include freezing (the growth of ice lenses), differential swelling (coupled with the weakening of interparticle forces during rapid wetting), and drying (shrinkage of a clay mass) (Katha, 2002).

Sharma (1998), through his work on the compaction of swelling soil, concluded that bentonite/kaolin samples compacted to $3200 \mathrm{kPa}$ during wetting/drying cycles achieved a net increase in volume over each wetting/drying cycle. The degree of saturation ( $\mathrm{Sr}$ ) varied significantly between the wetting and drying stages, and the Sr generally showed a net increase over each wetting/drying cycle. There is therefore the possibility that net shrinkage or swelling over a cycle may be linked to an irreversible variation of the $\mathrm{Sr}$ (hydraulic hysteresis).

Swelling clayey soils are also called expansive soils. When these soils are partially saturated, they increase in volume with the addition of water. They shrink greatly on drying and develop cracks on the surface. These soils have a high plasticity index. Black cotton soils found in many parts of India belong to this category. Their color varies from dark grey to black. It is easy to recognize these soils in the field during either dry or wet seasons. Shrinkage cracks are visible on the ground surface during dry seasons. The maximum width of these cracks may be up to $20 \mathrm{~mm}$ or more and travel deep into the ground. A lump of dry black cotton soil requires a hammer to break. During rainy seasons, these soils become very sticky and very difficult to traverse. Expansive soils are residual soils which are the result of the weathering of the parent rock. The depths of these soils in some regions may be up to $6 \mathrm{~m}$ or more. Normally the water table is encountered at great depths in these regions. As such, the soils only become wet during rainy seasons and are dry or partially saturated during the dry seasons. In regions which have well-defined, alternately wet and dry seasons, these soils swell and shrink in regular cycles. Since moisture changes in the soils bring about severe movements of the mass, any structure built on such soils experiences recurring cracking and progressive damage (Murthy, 2005).

Expansive soil originates from two sources: the first is igneous rocks, such as the basalts of the Deccan Plateau in India, which mainly consist of feldspar and pyroxene minerals, which decompose to form montmorilinite and expansive soil. The second group consists of sedimentary rocks which have been physically broken down to result in expansive soil (Chen, 1988). The expansive soils in Iraq are of the second group.

\section{GEOGRID ENCASED STONE OR SAND COLUMNS}

Geotextile-encased columns (GECs) have recently been used to extend sand columns to very soft and extremely soft soils. The technique has been successfully adopted in Europe and more recently in South America (Joel and Abdelmalek, 2010). The "overlap method" is considered likely to provide an efficient and costeffective alternative to welding. Using this technique, an encasement sleeve can be constructed from a geogrid with a nominal amount of circumferential overlap. The overlap method, where an interlock between a stone aggregate and an overlapped section of a geogrid encasement is used to prevent the encasement from unraveling, provides a level of fixity similar to welding.

A trial was conducted by Fattah and Majeed (2012) to improve the behavior of a stone column by encasing the stone column with a geogrid as reinforcement material. A parametric study was carried out to investigate the behavior of standard and encased floating stone columns in different conditions. Different parameters were studied to show their effect on the improvement of bearing and the settlement reduction of a stone column. These include the length- to-diameter ratio $(\mathrm{L} / \mathrm{d})$, the shear strength of the surrounding soil, the area replacement ratio $\left(\mathrm{a}_{\mathrm{s}}\right)$, etc. It was found that the maximum effective length-to-diameter ratio $(\mathrm{L} / \mathrm{d})$ is between (7-8) for shear strength $c_{u}$, between (20-40) $\mathrm{kPa}$ and between (10-11) for $\mathrm{c}_{\mathrm{u}}=10 \mathrm{kPa}$ for ordinary floating stone columns, while the effective $(\mathrm{L} / \mathrm{d})$ ratio is between (7-8) for encased floating stone columns. The increase in the area replacement ratio increases the bearing improvement ratio for encased floating stone columns, especially when the area replacement ratio is greater than $(0.25)$. The geogrid encasement of a stone column greatly decreases the lateral displacement compared with an ordinary stone column.

Fattah et al. (2014a and b) investigated the behavior of embankment models resting on soft soil reinforced with stone columns. Model tests were performed with different spacing distances between the stone columns and the two length-to-diameter ratios of the stone columns, in addition to the different embankment heights. A total number of 21 model tests were carried out on a soil with an undrained shear strength $\approx 10 \mathrm{kPa}$. The models consisted of stone column embankments with spacing-to-diameter ratios equal to 2.5 , 3 and 4 . The embankment models constructed on soft clay treated with ordinary stone columns at a spacing ratio equal to 2.5 revealed a maximum bearing improvement ratio equal to $(1.21,1.44$ and 1.7$)$ for $200 \mathrm{~mm}, 250 \mathrm{~mm}$ and 300 embankment heights, respectively, and the maximum settlement improvement ratio equaled $(0.78,0.67$ and 0.56$)$ for $200 \mathrm{~mm}, 250 \mathrm{~mm}$ and 300 embankment heights, respectively. The pore water pressure in the clay reinforced with encased stone columns decreased, and its dissipation consumed a shorter amount of time in comparison with the reinforced clay with ordinary stone columns.

\section{SWELL PRESSURE AND SWELL POTENTIAL}

Swelling pressure is a very useful index of the trouble potential of an expansive soil. This pressure is the minimum force per unit area that needs to be applied over a swelling soil to prevent an increase in volume. A swelling pressure of less than $20 \mathrm{kPa}$ may not be regarded as having much of a consequence. The swell potential of a soil in comparison is the magnitude of the heave of a soil for a given final water content and loading condition. Specially designed oedometer tests have been found quite useful to determine the magnitudes of these parameters for expansive soils (ASTM D4546-03).

\section{PROPOSED METHOD OF TREATMENT}

In the present paper, a method of treatment derived from the work of Al-Omari and Hamodi (1991) is employed. The method is simply based on the embedment of a geogrid (or a geomesh) in expansive soil. The geogrid is extended continuously inside the volume of the soil where the swell is required to be controlled and orientated towards the direction of the swell. As the present purpose is to control the swell and is not for the conventional purpose of improving shear strength, the following statement of Chen (1988) is recalled: "the mechanics of expansive soil are totally different from the theory of consolidation and the shearing strength of soils. It should be considered as a new phase of soil mechanics".

\section{FACTORS INFLUENCING SWELL POTENTIAL AND SWELL PRESSURE}

The swell potential and pressure are dependent on several factors; namely, the type and amount of clay minerals present, the initial dry density (void ratio) and water content of the soil specimen, the nature 
of the pore fluid, the types of exchangeable cations, the overburden pressure, and the wetting and drying effects (Chen, 1988; Day, 1994, Al-Homoud et al., 1995; Subba Rao et al., 2000). The swell potential and pressure are known to increase with any increase in the clay content and dry density and decrease with any increase in the initial water content, overburden pressure, pore salt concentration, and exchangeable cation valence (Chen, 1988; Mitchell, 1993). However, clay soils in arid and semi-arid regions are subjected to cycles of wetting and drying in the field due to climatic variations. The data of Day (1994), Al-Homoud et al. (1995), and Subba Rao et al. (2000) have illustrated that cyclic wetting and drying overrides the influence of the initial water content and void ratio on the swell potential of expansive clays. Direct methods provide actual physical measurements of swelling. Several laboratory methods have been developed to directly determine the swelling a soil undergoes as the moisture content changes. These include the free swell, expansion index, consolidation-swelling, California Bearing Ratio (CBR), potential volume change, and coefficient of linear extensibility methods.

In this paper, a treatment method for the swelling of expansive soil is presented. The method is based on the use of geogrid (or geomesh) columns in the soil. The geogrid is extended continuously inside the volume of the soil where the swell is required to be controlled and orientated towards the direction of the swell.

To investigate the swell, the swell- partial shrinkage, and other phenomena for untreated soils in comparison with their treated soil counterparts, numerical analyses were carried out using the finite element method.

\section{SIMULATION OF EXPERIMENTS}

Ali (2013) carried out experiments using a small model represented by a CBR to measure the swelling movement of reinforced samples in variable conditions. In addition, the effect of compacting efforts on the degree of the swelling was investigated.

Soils with different swelling potentials were employed. Na-base Bentonite and Ca-base Bentonite samples were brought from the city of Kirkuk in northern Iraq, while the non-expansive soil (Kaolinite) was brought from the State Company for Geological Surveys and Mining in Baghdad. The soil samples were prepared in the laboratory by mixing $30 \%$ of the Kaolinite with $70 \%$ of the Na- base Bentonite. Standard tests were performed to determine the physical and chemical properties of the soil. The physical properties of the soils are given in Table 1.

The modified free swell index, which was suggested by Sivapullaiah et al. (1987), was evaluated to get an indication of the swelling potential of the soil used. This test involves obtaining an oven-dried soil with a mass of about 10 grams. The soil mass was well pulverized and transferred into a $100 \mathrm{ml}$ graduated cylinder containing distilled water. After 24 hours, the swollen sediment volume was measured. The modified free swell index was then calculated as:

$$
\text { Modified free swell index }=\frac{(\mathrm{V}-\mathrm{Vs})}{\mathrm{Vs}}
$$

where:

$\mathrm{V}=$ soil volume after swelling,

$\mathrm{V}_{\mathrm{s}}=$ volume of soil solids $=\frac{W_{s}}{G_{s} \times \gamma_{w}}$,

$\mathrm{W}_{\mathrm{s}}=$ weight of oven-dried soil,

$\mathrm{g}_{\mathrm{w}}=$ unit weight of water, and

$\mathrm{G}_{\mathrm{s}}=$ specific gravity of soil solids.

Table 2 gives the expansive soil classifications based on the free swell ratio.

The plasticity indices for the soils used were 79, 82 and $100 \%$; the soil swelling potential was classified as very high based on the modified free swell index. Sand was used in the geocell columns. The sand was of a uniform size with a poorly graded gradation. The physical properties of the sand are presented in Table 3 .

The isolated geocell was filled with the same soil or filled with sand; the geocell was prepared by rolling a geogrid mesh with a specified diameter $(20,30$ or $50 \mathrm{~mm})$ fixed with steel wire. A hole was made in the sample by a drilling machine after compacting the three layers as proposed in the swelling soil treatment method.

Tab. 1 Physical properties of the soils used in the experimental work of Ali (2013).

\begin{tabular}{|l|c|c|c|c|}
\hline Sample Designations & Test Method & Sample 1 (S1) & Sample 2 (S3) & Sample 3 (S2) \\
\hline Description & & Ca-base Bentonite & Na-base Bentonite & $\begin{array}{c}30 \% \text { kaolinite } 70 \% \\
\text { Na-base bentonite }\end{array}$ \\
\hline Liquid limit, L.L\% & ASTM D4318-00 & 125 & 155 & 130 \\
\hline Plastic limit, P.L \% & ASTM D4318-00 & 46 & 55 & 48 \\
\hline Plasticity index, P.I \% & & 79 & 100 & 82 \\
\hline Specific gravity, Gs & ASTM D854-05 & 2.75 & 2.78 & 2.70 \\
\hline \% Finer than 0.005 mm & & 95 & 97 & 88 \\
\hline
\end{tabular}

Tab. 2 Expansive soil classification based on a free swell ratio (from Sridharan et al., 1987).

\begin{tabular}{|c|c|c|c|}
\hline Free swell ratio & Clay type & Potential swell classification & Dominant clay mineral \\
\hline$\leq 1.0$ & Non-swelling & Negligible & Kaolinite \\
\hline $1.0-1.5$ & Mixture of swelling and non-swelling & Low & Kaolinite and montmorillonite \\
\hline $1.5-2.0$ & Swelling & Moderate & Montmorillonite \\
\hline $2.0-4.0$ & Swelling & High & Montmorillonite \\
\hline$>4.0$ & Swelling & Very High & Montmorillonite \\
\hline
\end{tabular}


Tab. 3 Physical and chemical properties of the sand fill used (after Ali, 2013).

\begin{tabular}{|l|l|}
\hline Index property & Index value \\
\hline Max. dry unit weight $\left(\mathrm{kN} / \mathrm{m}^{3}\right)$ & 17.4 \\
\hline Min. dry unit weight $\left(\mathrm{kN} / \mathrm{m}^{3}\right)$ & 14.4 \\
\hline Dry unit weight used $\left(\mathrm{kN} / \mathrm{m}^{3}\right)$ at $\mathrm{Dr}=23 \%$ & 15.2 \\
\hline$e_{\min }$ & 0.59 \\
\hline$e_{\max }$ & 0.82 \\
\hline$e_{\text {used }}$ at dry unit weight used & 0.76 \\
\hline Specific gravity $(\mathrm{Gs})$ & 2.63 \\
\hline Coefficient of uniformity $\left(\mathrm{C}_{\mathrm{u}}\right)$ & 2.67 \\
\hline Coefficient of curvature $\left(\mathrm{C}_{\mathrm{c}}\right)$ & 1 \\
\hline Total soluble salts, T.S.S $(\%)$ & 15.7 \\
\hline So ${ }_{3}(\%)$ & 3.121 \\
\hline Organic matter $(\%)$ & 1.46 \\
\hline Relative density $\left(\mathrm{D}_{\mathrm{r}} \%\right)$ & 23 \\
\hline Angle of internal friction $\left(\mathrm{f}^{\circ}\right)$ at $\mathrm{D}_{\mathrm{r}}=23 \%$ & $28^{*}$ \\
\hline
\end{tabular}

Figure 1 illustrates the geocell filled with the same soil or with sand. A perforated steel cap was placed above the compacted samples with a filter paper in between them, and a constant dead load of $(5 \mathrm{kPa})$ was applied (Ali, 2013). Table 4 defines each model by a relevant symbol.

The improvement factor (IF) is defined as the difference between the final swell of the unreinforced sample, $\mathrm{W}_{\mathrm{u}}$, and the final swell of the corresponding reinforced sample, $\mathrm{W}_{\mathrm{r}}$, divided by the final unreinforced swell, thus (Al-Omari and Hamodi, 1991):

$$
\mathrm{IF}=\frac{\mathrm{W}_{\mathrm{u}}-\mathrm{W}_{\mathrm{r}}}{\mathrm{W}_{\mathrm{u}}}
$$

$\mathrm{W}_{\mathrm{r}}$ and $\mathrm{W}_{u}$ are determined from the swelling test (ASTM D4546$03)$. The value of $\mathrm{W}_{\mathrm{r}}$ is corrected for the unreinforced length as the soil sample's height is slightly larger than the geocell height.

\section{COMPUTATIONAL MODELING USING THE FINITE ELEMEMT METHOD}

The FEM is a numerical method that seeks an approximated solution of the distribution of field variables in a problem domain that is difficult to obtain analytically. It is performed by dividing the problem domain into several elements (Liu and Quek, 2003).

Using the ABAQUS finite element software, two effects, i.e., "gel" swelling and moisture swelling, may be included in partially saturated cases. These are usually associated with the modeling of moisture absorption into polymeric systems (such as paper towels) rather than with geotechnical systems and are not discussed in the notes in (ABAQUS Theory Manual, 2009).

The total stress acting on a point, $\sigma$, is assumed to be made up of an average pressure stress in the wetting fluid, i.e., $u_{w}$, called the "pore pressure" times a factor, $\chi$, and an "effective stress" in the material skeleton, $\bar{\sigma}$.

$$
\bar{\sigma}=\sigma+\chi \times u_{w} \times I
$$

Tab. 4 Model types and their signs.

\begin{tabular}{|l|c|}
\hline \multicolumn{1}{|c|}{ Sample type } & Sample symbol \\
\hline Ca-base Bentonite sample & $\mathrm{S}_{1}$ \\
\hline Na-base Bentonite sample & $\mathrm{S}_{3}$ \\
\hline $\begin{array}{l}\text { Mixture } 70 \% \text { Na-baseBentonite sample with } \\
30 \% \text { Kaolinite }\end{array}$ & $\mathrm{S}_{2}$ \\
\hline Geogrid No. 1 (stiffness $=120 \mathrm{kN} / \mathrm{m}$ ) & $\mathrm{G}_{1}$ \\
\hline Geogrid No. 2 (stiffness $=40 \mathrm{kN} / \mathrm{m}$ ) & $\mathrm{G}_{2}$ \\
\hline Geocell filled with the same soil & $\mathrm{F}_{1}$ \\
\hline Geocell filled with sand & $\mathrm{F}_{2}$ \\
\hline
\end{tabular}

In general, $\chi=\chi(\mathrm{s})$ can be measured experimentally. Since data relating $\chi$ to $S$ are difficult to obtain, ABAQUS assumes $\chi=S$ (degree of saturation).

The effective stress principle is the assumption that the constitutive response of a porous medium consists of simple bulk elasticity relationships for the fluid and the solid grains, together with a constitutive theory for the material skeleton, whereby $\bar{\sigma}$ is defined as a function of the strain history and temperature of the material (ABAQUS Theory Manual, 2009): $\bar{\sigma}=\bar{\sigma}$ (strain history, temperature, state variables)

The strain rate decomposition is then:

$$
d \varepsilon=\left(d \varepsilon_{g}^{v o l}+d \varepsilon_{w}^{v o l}\right) I+d \varepsilon^{e l}+d \varepsilon^{p l}
$$

where: $d \varepsilon_{g}^{v o l}, d \varepsilon_{w}^{v o l}:$ the volume strain rates in the solid grains and fluid respectively,

$d \varepsilon^{e l}, d \varepsilon^{p l}:$ the elastic and plastic strain rates in the material skeleton respectively, and

$I$ : a saturation dependency for the isotropic materials.

The stress equilibrium for the solid phase of the material is expressed by writing the principle of the virtual work for the volume under consideration in its current configuration at time $t$ :

$$
\int_{V}\left(\bar{\sigma}-\chi u_{w} I\right): \delta g d V=\int_{S} t \cdot \delta v d S+\int_{V} f \cdot \delta v d V+\int_{V} s n \rho_{w} g \cdot \delta v d V
$$

where:

$\partial \varepsilon=\operatorname{sym}(\partial \delta v / \partial x)$ is the virtual rate of the deformation,

$\bar{\sigma}$ the true (Cauchy) effective stress,

$\delta v$ is a virtual velocity field,

$t$ surface tractions per unit area,

$f$ body forces (excluding fluid weight) per unit volume,

$\rho_{w}$ the density of the fluid, and

$g$ the gravitational acceleration (assumed constant and in a fixed direction).

This equation is then discretized using a lagrangian formulation for the solid phase, with any displacements as the nodal variable.

The porous medium is thus modeled by attaching the finite element mesh to the solid phase. Fluid may flow through this mesh (ABAQUS Theory Manual, 2009).

In order to model elasto-plastic material using ABAQUS, either linear elasticity or nonlinear porous elasticity ought to be used with it. The Drucker-Prager/cap plasticity model has been widely used in finite element analysis programs for a variety of geotechnical engineering applications. The cap model is appropriate for soil behavior, because it is capable of considering the effect of the stress history, stress path, dilatancy, and the intermediate principal stress. 


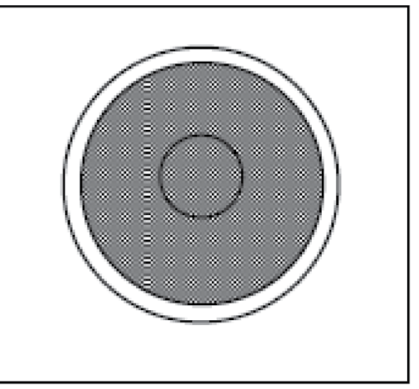

a- CBR-sample treated with a geocell filled with the same soil.

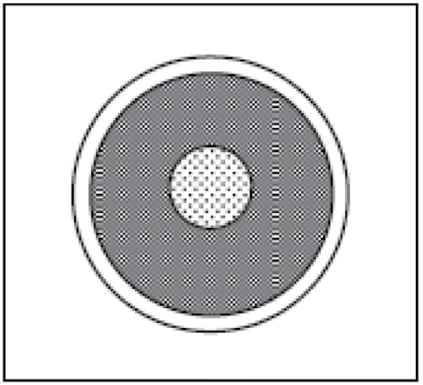

b- CBR-sample treated with a geocell filled with sand.

Fig. 1 Geogrid cell-treated soil in the CBR mold.

The yield surface of the modified Drucker-Prager/cap plasticity model consists of three parts: a Drucker-Prager shear failure surface; an elliptical cap, which intersects the mean effective stress axis at a right angle; and a smooth transition region between the shear failure surface and the cap (ABAQUS Applications, 2007).

\section{MODELING OF THE GEOCELL COLUMNS WITH ABAQUS}

In order to account for the elasto-plastic condition in the elastic behavior of the surrounding soil, a numerical approach based on the finite element method was utilized to analyze the problem at hand. A two-dimensional analysis is suitable since both the geometry and loading are in an approximate state of plane strain. The analysis of a single geocell and three geocells embedded in an expansive soil was divided into three components, mainly the geocell material, the fill materials and the swelling zone. Figures 2 and 3 represent a general view of the cases studied. The adopted mesh size was made to be fine near the geocell where the deformations and the stresses change abruptly. Figure 4 demonstrates the mesh used to analyze the single geocell fill material.

The geogrid surrounding the geocell is assumed to be a linear, elastic material throughout the analysis. The geocell properties adopted in this analysis are as shown in Table 5.

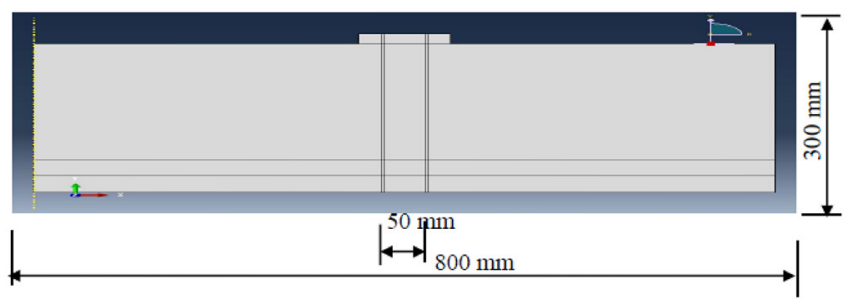

Fig. 2 View of a single geocell in expansive soil.

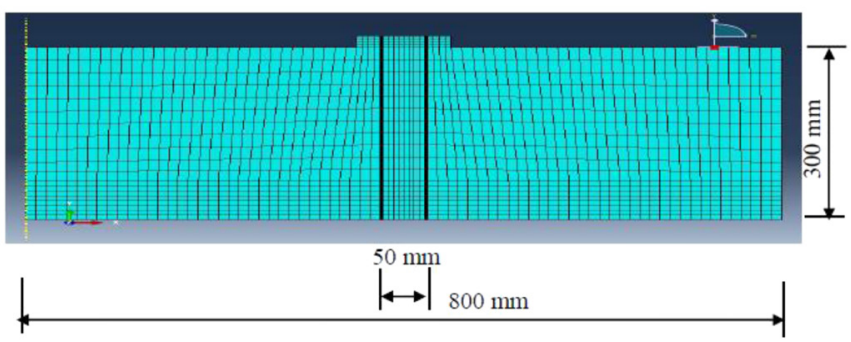

Fig. 3 Mesh of a single geocell in expansive soil.

Tab. 5 Physical properties of the geocell used.

\begin{tabular}{|c|c|c|c|c|}
\hline $\begin{array}{c}\text { Type of } \\
\text { geocell }\end{array}$ & $\begin{array}{c}\text { Length } \\
(\mathbf{m m})\end{array}$ & $\begin{array}{c}\text { Mass per unit } \\
\text { length } \mathbf{( g m} / \mathbf{m}^{\mathbf{2}} \mathbf{)}\end{array}$ & $\begin{array}{c}\text { Stiffness } \\
\mathbf{( k N / m )}\end{array}$ & $\begin{array}{c}\text { Poisson's } \\
\text { ratio, } \mathbf{v}\end{array}$ \\
\hline G1 & 350 & 700 & 120 & 0.15 \\
\hline G3 & 350 & 300 & 240 & 0.18 \\
\hline
\end{tabular}

The soil was assumed to behave as an elasto-plastic material throughout this analysis with the properties summarized in Tables 6 and 7.

A modified Druche-Prager/cap plasticity model is used to simulate the geological materials, which exhibit a pressure-dependent yield. The addition of a cap yield surface helps the constant volume dilatancy when the material yields in shear and provides an inelastic hardening mechanism to represent the plastic compaction. The parameter of the initial cap yield surface position used is 0 .

Tab. 6 Engineering properties of the swelling zone and the fill material used (after Ali, 2013).

\begin{tabular}{|c|c|c|c|c|c|c|c|c|}
\hline Type of Soil & $\gamma_{\mathbf{d}}\left(\mathbf{g m} / \mathbf{c m}^{3}\right)$ & $\begin{array}{c}\text { Modulus of } \\
\text { Elasticity* } \\
\mathbf{( k P a )}\end{array}$ & $\begin{array}{c}\text { Poisson's } \\
\text { ratio, } \mathbf{v}\end{array}$ & $\mathbf{e}_{\boldsymbol{o}}$ & $\begin{array}{c}\text { Undrained } \\
\text { shear stress, } \mathbf{c}_{\mathbf{u}} \\
\mathbf{( k P a )}\end{array}$ & $\begin{array}{c}\text { Angle of } \\
\text { internal friction, } \\
\Phi^{\circ}\end{array}$ & $\begin{array}{c}\text { Flow } \\
\text { stress } \\
\text { ratio }\end{array}$ & $\begin{array}{c}\text { Transition } \\
\text { surface radius } \\
\mathbf{p a r a m e t e r}\end{array}$ \\
\hline $\mathrm{S} 2(\mathrm{~F} 1)$ & 1.350 & $* 10500$ & 0.49 & 0.89 & 21 & 0 & 1 & 0.05 \\
\hline S3 (F1) & 1.275 & $* 8750$ & 0.49 & 1.32 & 16.5 & 0 & 1 & 0.05 \\
\hline F2 & 1.52 & $* * 15000$ & 0.33 & 0.76 & - & 28 & 1 & 0.05 \\
\hline
\end{tabular}

Tab. 7 Values of the parameters used in the swelling zone (after Ali, 2013).

\begin{tabular}{|c|c|c|c|c|}
\hline Soil Type & Degree of saturation $\%$ & Swelling strain \% & Matric suction, $\mathrm{kPa}$ & Coefficient of permeability, $\mathrm{k}_{w}(\mathrm{~mm} / \mathrm{min})$ \\
\hline \multirow{3}{*}{ S2 } & 33 & 0 & -18.5 & \multirow{3}{*}{$9.43 \times 10^{-6}$} \\
\hline & 60 & 0.058 & -18 & \\
\hline & 100 & 0.089 & -17.5 & \\
\hline \multirow{3}{*}{ S3 } & 33 & 0 & -19.5 & \multirow{3}{*}{$8.94 \times 10^{-6}$} \\
\hline & 60 & 0.077 & -19 & \\
\hline & 100 & 0.11 & -18.5 & \\
\hline
\end{tabular}




\section{INTERACTION MODEL}

Interaction models are used to manage the mechanical and thermal interactions between the regions of the model and the surrounding material. ABAQUS provides more than one model to simulate the interaction between the surfaces. The surface-to-surface contact is used to describe the contact between two deformable surfaces or between a deformable surface and a solid surface. The choice of these surfaces has a small influence on the results when using a surface-tosurface contact compared with the other choices.

Boundary conditions should be used to specify the values of all the solutions such as displacement/rotation and fluid pressure. The boundary conditions should be chosen and carefully identified to represent the entire actual domain in terms of in-situ stresses and displacements. The boundary conditions are assumed to be hinged at the end and at each side of the soil to prevent horizontal and vertical lower movements. Figure 4 demonstrates the boundary conditions of some cases of the study.

The steady-state coupled pore pressure/effective stress analysis is assumed. The pore pressure and stresses are modeled with the eight-noded quadrilateral elements, which are assumed to model the swelling soil, geocell fill materials, and the lower soil.

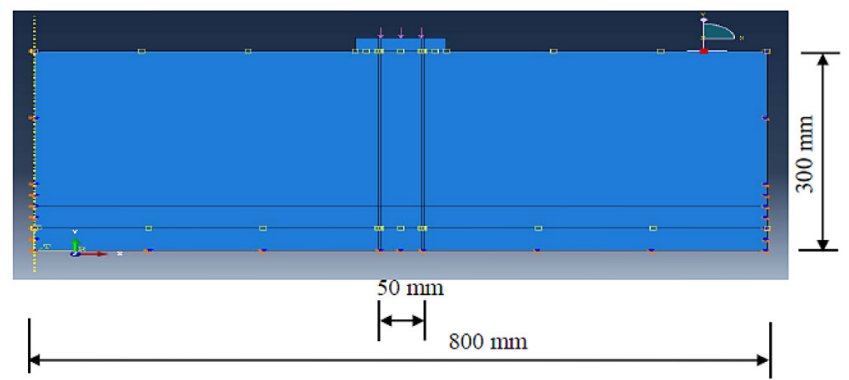

Fig. 4 Boundary conditions of one geocell model in the expansive soil model.

\section{RESULTS AND DISCUSSION OF THE FINITE ELEMENT ANALYSIS}

A parametric study was conducted to study the effect of some factors that affect the geocell system's behavior. Some parameters were varied through their reasonable ranges in order to establish their effect on the swell-time, load-settlement and consolidation characteristics of shallow foundations.

\section{Effect of the angle of friction of the fill material in the geocell column}

Two fill materials were used that had different values of the angle of friction: the first granular material has an angle of friction of $\left(28^{\circ}\right)$, while the second material has the same swelling soil with $\left(\phi=0^{\circ}\right)$. The first soil is classified as "very loose", while the second is classified according to the unified soil classification system as " $(\mathrm{CH})$ fat clay.

It can be noted from Figures 5 to 7 that the swell-depth relationships for the two cases of the $\mathrm{S} 3$ soil sample provide indications about the effect of the fill material. A noticeable improvement in the restriction can be obtained when the angle of friction of the column material increases. The effect of the angle of friction on the restriction is shown in Figures 5 and 7.

The degree of saturation and the matric suction (negative pore water pressure) slightly decrease as the angle of friction of the geocell column material increases, as can be seen in Figure 7, due to the activity of the sand filling the geocell column in a dissipation of the negative pore water pressure and accelerating the drainage through its function as a sand drain.

Figures 5 and 8 show the effect of the treatment method on the swell calculated by the finite elements through the ABAQUS program. This is a good indication about the method of treatment with the geocell filled with sand, which provided an improvement factor equal to $(62 \%)$. The method of treatment by a geocell filled with the same soil revealed an improvement factor equal to (51\%), while the S3 soil treated with the geocell filled with sand showed an improvement factor of $(54.7 \%)$. For the S2 soil sample treated with a geocell filled with the same soil, the improvement factor is $34.4 \%$.

\section{Effect of the soil plasticity index on the treatment by a geocell filled with different materials}

To show the effect of the plasticity index of the swelling soil or the degree of the swelling index on the activity of the treatment method, the S2 soil sample was chosen for analyses by the ABAQUS program. Figures 8 and 9 show the results of the analysis compared with the results of the analysis of the $\mathrm{S} 3$ soil sample with and without treatment, as shown in Figures 5 to 7.

It can be seen from the results that when the plasticity index and the active depth (the active zone is considered to be equal to the overall depth of the clay model) increase, the axial movement (swelling movement) and matric suction vary between a maximum value at the top of the layer and a minimum value in the last third of the active depth and then change to compression at the end of the layer as a result of the increase in axial forces.

These figures illustrate the role of sand in controlling the flow of water, which leads to understanding the higher values of matric suction in sand compared with clay. The sand in the geocell continues to work as a drain during the analysis time, which leads to high values of the matric suction at all times.

\section{Effect of the elastic modulus of the geogrid material}

Geogrids are made from polymer materials; the typical range of the elastic modulus (E) for polymers is listed in Table 8. In order to investigate the effect of the elastic modulus on the settlement ratio, a model of cohesive swelling soil with a geocell-filled column having a diameter of $50 \mathrm{~mm}$, a length-to-diameter ratio $(\mathrm{L} / \mathrm{D}=6)$ with spacing of (2) times the footing width (B), and one column of the G1 or G3 geogrid type, respectively, was analyzed with stiffness for the polymer materials (120 and 240) $\mathrm{kPa}$. As can be seen in Figures 10 to 15 compared with Figures 5 to 7 , the effect of the elastic modulus of the geogrid on the swelling, pore water pressure, and degree of saturation decreases slightly when the elastic modulus increases. Subsequently, the effect diminishes gradually with the depth. This can be attributed to the stiffness of the geogrid, which leads to the restriction of soil movement and the concentration of stresses within the geocell, hence decreasing the swelling and pore water pressure.

The geogrid stiffness greater than that of G1 has a slight effect compared with the cost of the geogrid materials.

Figures 13 to 15 show the predicted swelling and pore water pressure at different locations. The improvement factor (IF) for the S3 soil sample treated with G1F2 is $48 \%$, but this factor is $56 \%$ for the $\mathrm{S} 3$ soil sample treated with G3F2; in addition, the matric suction decreases by a ratio of $10 \%$ for the soil treated with G3F2. 
Tab. 8 Elastic modulus ranges for polymer materials (Giannelis, 1996).

\begin{tabular}{|c|c|}
\hline Material & Elastic Modulus (MPa) \\
\hline Polyamides & $3000-5000$ \\
\hline Polyesters & $1000-5000$ \\
\hline Nylon & $2000-4000$ \\
\hline Polystyrene & $3000-3400$ \\
\hline Polyethylene & $200-700$ \\
\hline Rubbers & $10-100$ \\
\hline
\end{tabular}

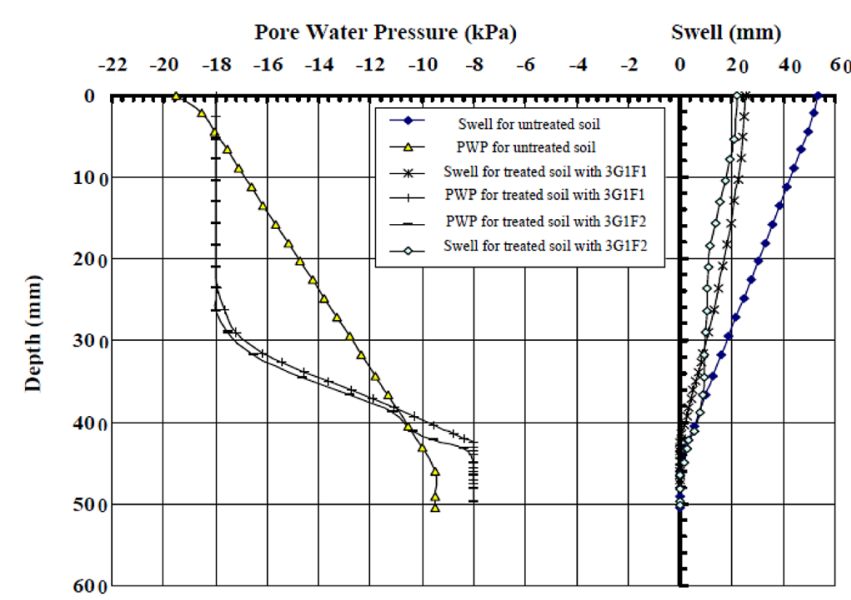

Fig. 6 Distribution of the predicted swell and pore water pressure with the depth for the average of the axes $B$ and $C$ in the $S 3$ soil sample with and without treatment with geocells.

Pore Water Pressure (kPa) Swell (mm)

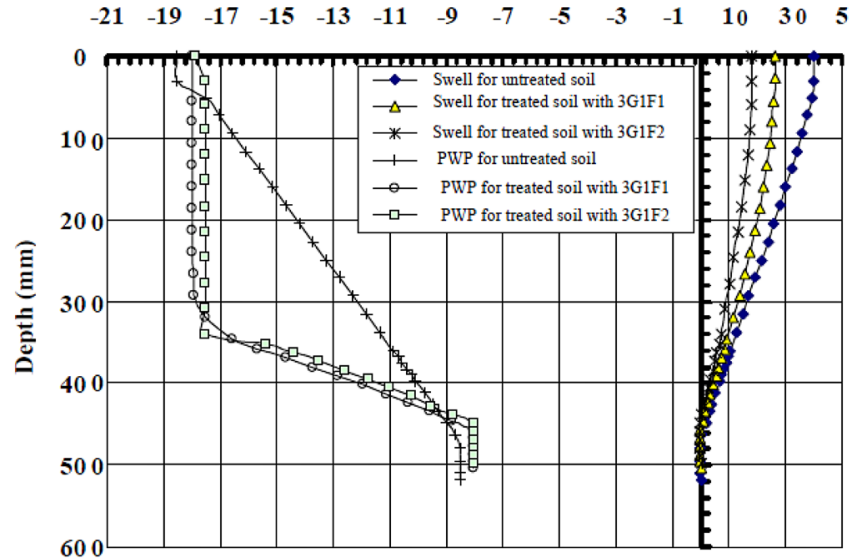

Fig. 8 Variation of the predicted swell and pore water pressure with the depth along axis A in the $S 2$ soil sample with and without treatment with geocells.

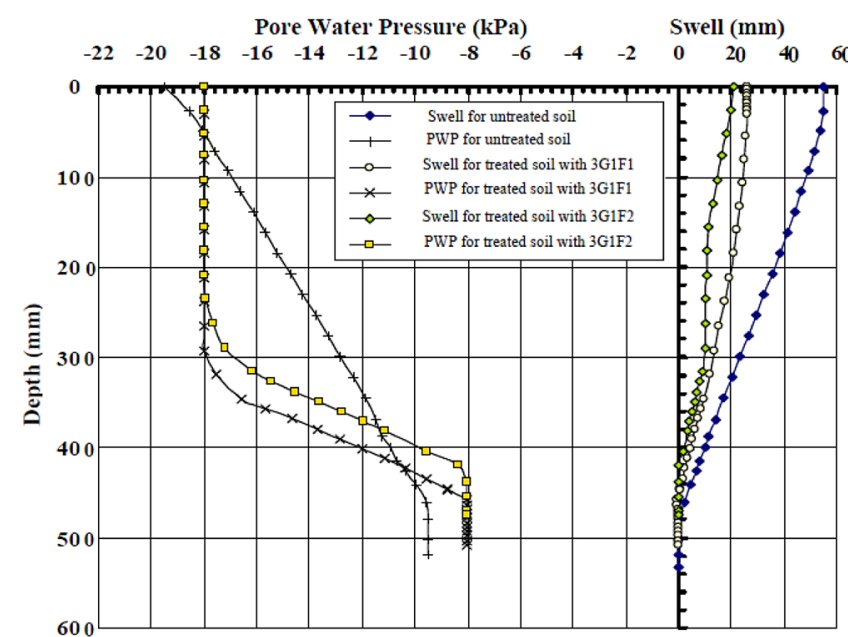

Fig. 5 Distribution of the predicted swell and pore water pressure with the depth along axis $A$ in the $S 3$ soil sample with and without treatment.

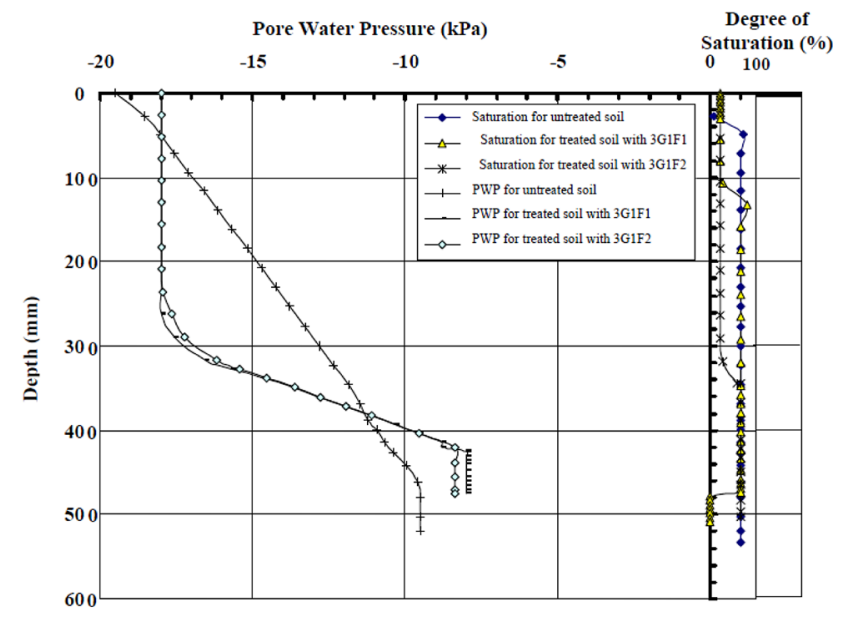

Fig. 7 Distribution of the degree of saturation and pore water pressure with the depth along axis $A$ in the $S 3$ soil sample with and without treatment with a geocell.

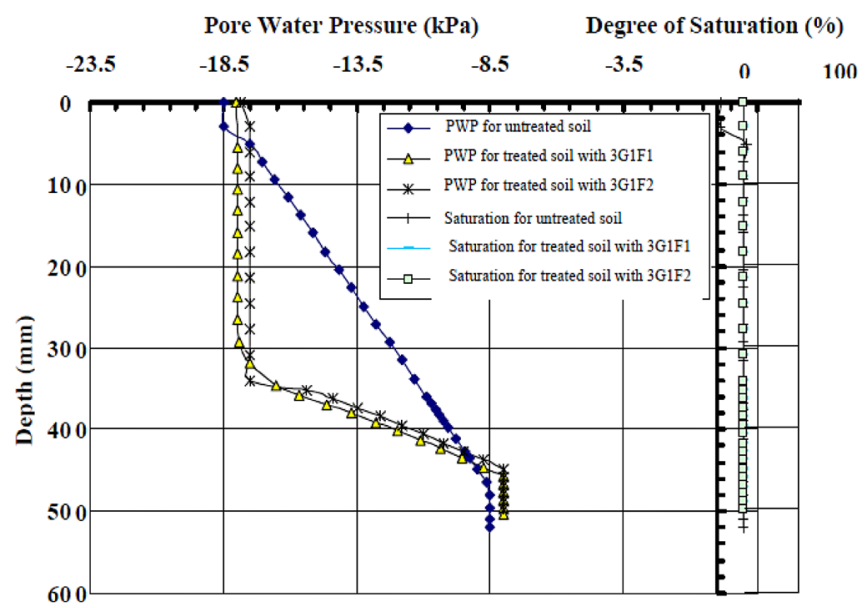

Fig. 9 Variation of the predicted degree of saturation and pore water pressure with the depth along axis A in the $S 2$ soil sample with and without treatment with geocells. 


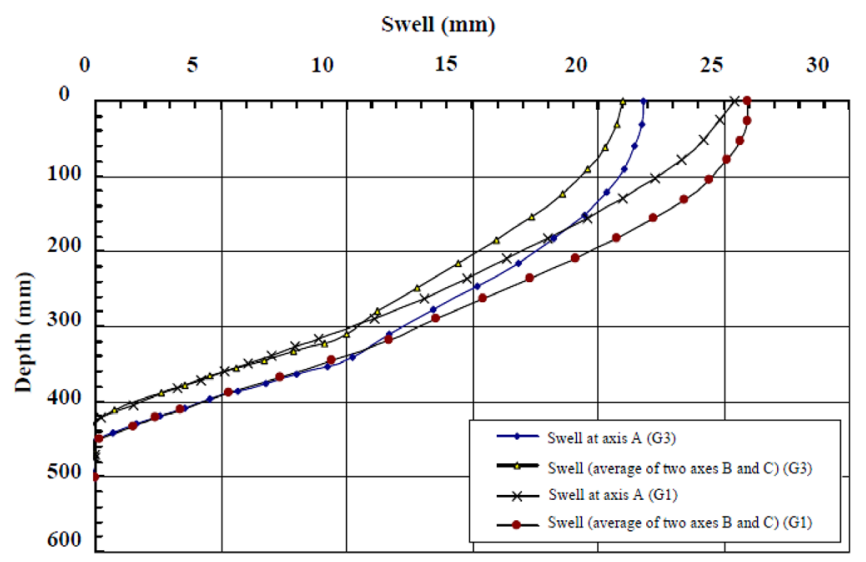

Fig. 10 Variation of the predicted swell with the depth along axis $A$ in the $S 3$ soil sample treated with geocells encased by different geogrids.

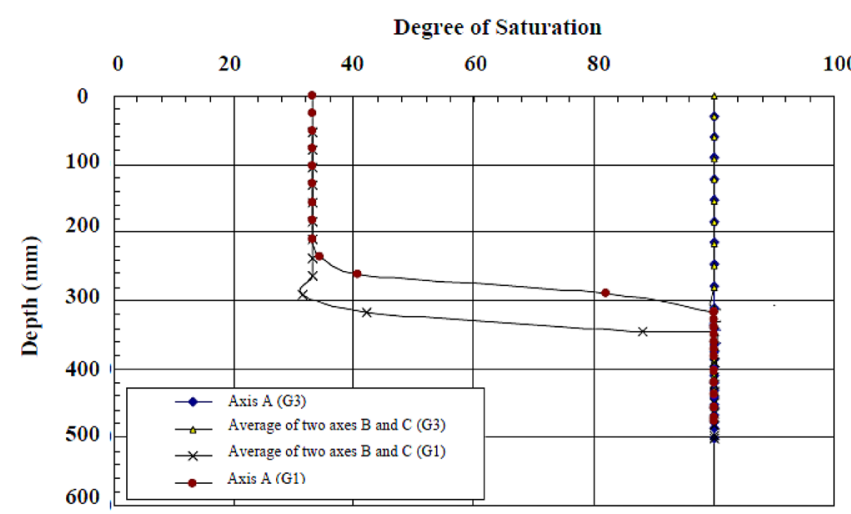

Fig. 12 Variation of the predicted degree of saturation with the depth along axis $A$ in the $S 3$ soil sample treated with different geocells encased by different geogrids.

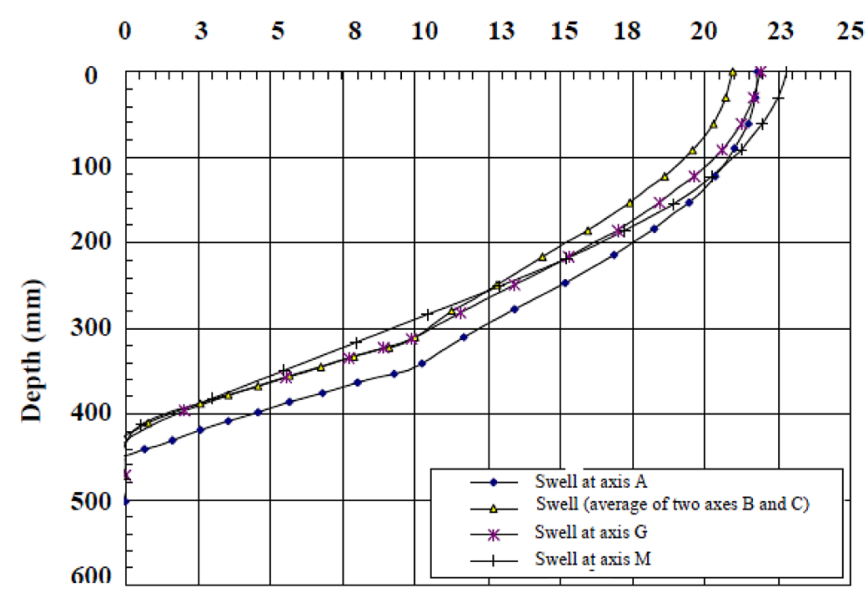

Fig. 14 Variation of the predicted swell with the depth for the $S 3$ soil sample treated by 3 geocell columns $(G 3 F 2$, diameter $=5 \mathrm{~cm})$ along axes $A, B, C, G$ and $M$.

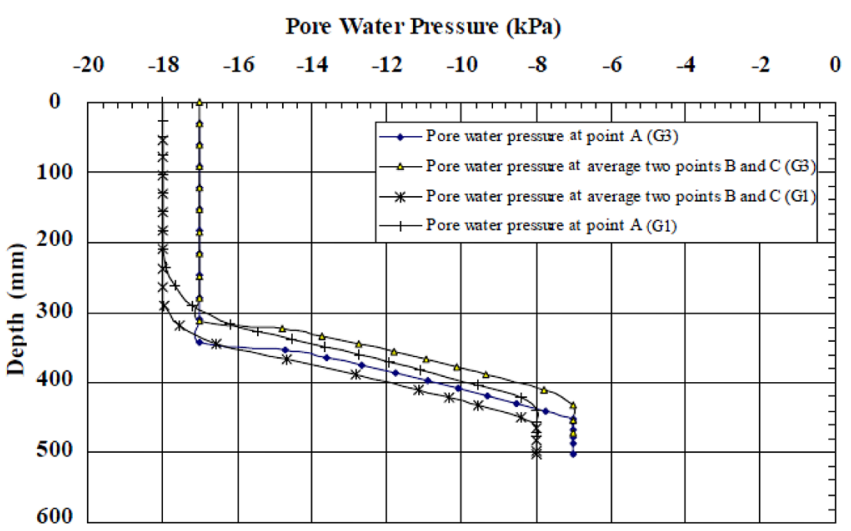

Fig. 11 Variation of the predicted pore water pressure with the depth along axis $A$ in the $S 3$ soil sample treated with geocells encased by different geogrids.

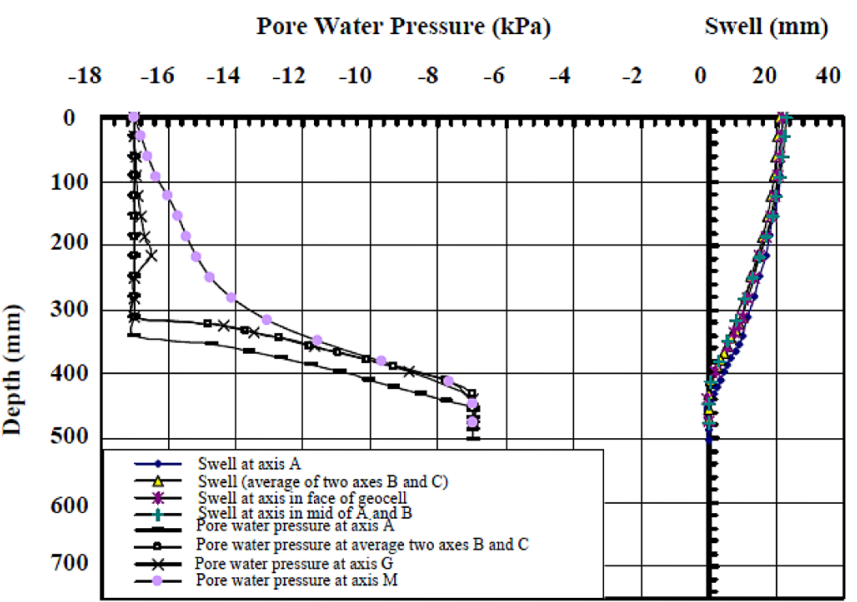

Fig. 13 Variation of the predicted swell and pore water pressure with the depth along axes $A$, the average of two axes $B$ and $C, G$ and $M$ in the $S 3$ soil sample treated by 3 geocell columns (G3F2, diameter $=5 \mathrm{~cm}$ ) at different locations.

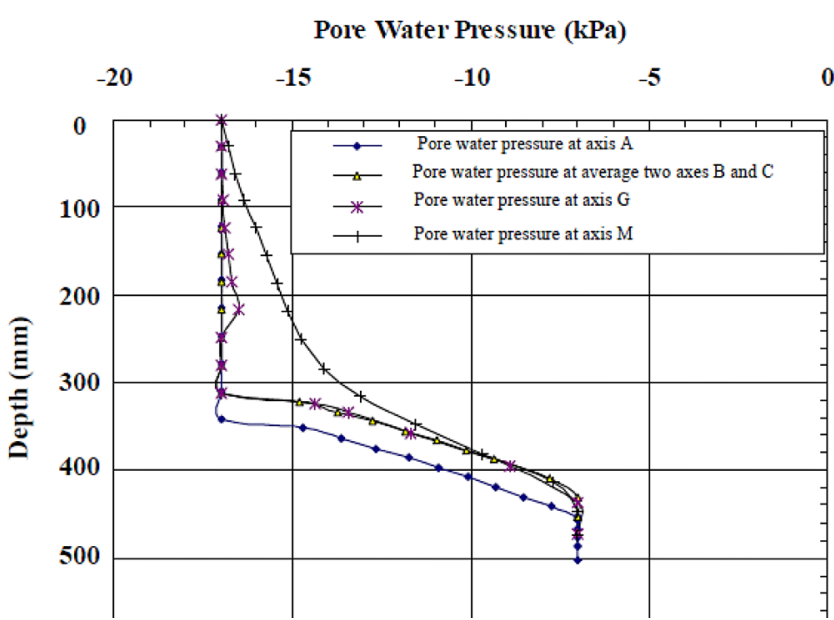

Fig. 15 Variation of the predicted pore water pressure with the depth for the $S 3$ soil sample treated by 3 geocell columns $(G 3 F 2$, diameter $=5 \mathrm{~cm}$ ) along axes $A, B, C, G$ and $M$. 


\section{CONCLUSIONS}

The results of the finite element analysis reveal the following conclusions:

1. The degree of saturation and the matric suction (negative pore water pressure) decrease as the angle of the friction of the geocell column material increases due to the activity of the sand fill in dissipation of the pore water pressure and accelerate the drainage through its function as a drain.

2. When the plasticity index and the active depth (the active zone is considered to be equal to the overall depth of the clay model) increase, the axial movement (swelling movement) and matric suction, as a result of the increase of the axial forces, vary between the maximum value at the top of the layer and a minimum value in the last third of the active depth and then return to consolidation at the end of the depth layer.

3. The effect of the geogrid stiffness on the swelling, pore water pressure and degree of saturation decreases slightly when the elastic modulus increases. Subsequently, the effect diminishes gradually with the depth. 


\section{REFERENCES}

ABAQUS Applications (2007) Applied soil mechanics, Sam Helwany, John Wiley \& Sons, Inc.

ABAQUS Theory Manual (2009) version 6.1: Hibbitt, Karlsson \& Sorenson, Inc.

Al-Homoud, A. S. - Husein M. B. - Al-Bashabshah, M. A. (1995) Cyclic swelling behavior of clays, Journal of Geotechnical Engineering, ASCE 121, pp. 582-585.

Al-Omari, R. R. - Hamodi, F. J. (1991) Swelling resistant geogrid: a new approach for the treatment of expansive soils, Geotextile and Geomembranes, Vol. 10, pp. 295-317.

Ali, H. A. (2013) Experimental investigation and numerical analysis of geocell encased columns in highly expansive soils, Ph.D. thesis, Al-Nahrain University, Baghdad, Iraq.

ASTM D 4546-03 (2004) Standard Test Methods for One-Dimensional Swell or Settlement Potential of Cohesive Soils, American Society for Testing and Materials. Philadelphia, PA: American Society for Testing and Materials.

Chen, F. H. (1988) Foundations on expansive soils, Developments in Geotechnical Engineering, Vol. 12, Elsevier Publications, the Netherlands.

Day, R. W. (1994) Swell-shrink behavior of compacted clay, Journal of Geotechnical Engineering, ASCE, Vol. 120, pp. 618-623.

Fattah, M. Y. - Majeed, Q. G. (2012) Finite element analysis of geogrid encased stone columns, Geotechnical and Geological Engineering Journal, Springer Science and Business Media B.V. 2012, DOI 10.1007/s10706-011-9488-8, 30, pp. 713-726.

Fattah, M. Y. - Zabar, B. S. - Hassan, H. A. (2014a) An Experimental Analysis of Embankment on Stone Columns, Journal of Engineering, University of Baghdad, Vol. 20, No. 7, pp. 62-84.
Fattah, M. Y. - Zabar, B. S. - Hassan, H. A. (2014b) Behavior of Soft Clay Strengthened by Geogrid Encased Stone Columns underneath Embankment, International Conference for Engineering Sciences - University of Mustansiriya, Baghdad, 26-27 March 2014, Vol. 2, pp. 70-99.

Giannelis E. P. (1996) Materials by design, Report submitted to Department of Materials Science and Engineering in Cornell University, USA.

Joel, G. I. - Abdelmalek, B. G. (2010) Construction of geogrid encased stone columns: A new proposal based on laboratory testing, Geotextiles and Geomembranes, 28, pp. 108-118.

Katha, B. R. (2002) Shrinkage strain characterization of expansive soils using digital imaging technology, M.Sc. Thesis, The University of Texas at Arlington, Texas, $101 \mathrm{pp}$.

Liu, G. R. - Quek, S. S. (2003) The finite element method, A Practical Course, Department of Mechanical Engineering, National University of Singapore.

Mitchell, J.K. (1993) Fundamentals of soil behavior, John Wiley and Sons, New York.

Murthy, V. N. S. (2005) Geotechnical engineering - principles and practices of soil mechanics and foundation engineering, Marcel Dekker Inc., New York.

Sharma, R. S. (1998) Mechanical behavior of unsaturated highly expansive clays, Ph.D. thesis, Kebel College, University of Oxford.

Sivapullaiah, P. V. - Sitharam, T. G., - Subba Rao, K. S. (1987) Clay-organic molecule interaction: consolidation behavior. Clay Res., 6(2), pp. 76-80.

Subba Rao - Rao S. M. - Gangadhara, S. (2000) Swelling behavior of desiccated clay, ASTM, Geotechnical Testing Journal, 23, pp. 193-198. 